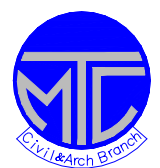

ICCAE

Military Technical College

Kobry Elkobbah, Cairo, Egypt 6h International Conference

On Civil \& Architecture

Engineering

\title{
Numerical Modeling of Soil-Tunnel Interaction under New Surface Load
}

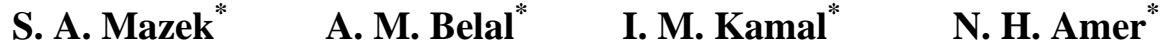

\begin{abstract}
El-Azhar road tunnels, a major project of underground structures in Cairo, Egypt, were constructed by the tunneling boring machine (TBM). During construction of a proposed building over the existing El-Azhar road tunnels, Geotechnical challenges are expected to occur. An example of these challenges arises when the proposed building is constructed over the existing southern road tunnel. However, the serious damage in the road tunnel liners is predicted and the maximum radial displacement of the road tunnel is also computed. The allowable radial displacement of the road tunnel liners when the proposed building is constructed over the road tunnels should be checked within the allowable limit of $10 \mathrm{~mm}$ set by the Egyptian Standards.

In the present study, the prediction of the impact of the proposed building construction on ElAzhar tunnels is highlighted and a model is proposed to study the soil structure interaction using a 2-D model of the proposed building on EI-Azhar tunnels. The study is conducted using Finite Element Method. The constitutive model for this analysis contains elasto-plastic materials. A yielding function of the Mohr-Coulomb type and a plastic potential function of the Drucker-Prager type are employed. A linear constitutive model is employed to represent the tunnel liners.

The effects are expressed in terms of settlement and radial deformation in the road tunnels. The study includes the prediction of the settlement, the relative movements, and the lining stress under different loading steps. The description of the used model, the output results, and the final conclusion are presented in this paper.
\end{abstract}

Keywords: Tunnels, tunneling, settlement, numerical modeling and analysis, nonlinear displacement, design, deformations.

${ }^{*}$ Egyptian Armed Forces. 
Proceedings of the 6th ICCAE Conf. 16-18 May, 2006

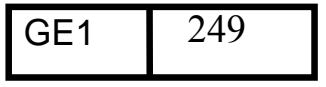

\section{INTRODUCTION}

El-Azhar road tunnels are $2.7 \mathrm{~km}$ long. Many problems related to the soil stability were expected during the construction of the proposed building over southern road tunnel at El Azhar district. The road tunnels pass 18 metres beneath the foundation level of the proposed building, as shown in Figure 1. The tunnel lining is built of pre-cast reinforced concrete. The structural system of the building is reinforced concrete skeleton on rigid shallow foundation. The total area of the proposed building is about $500 \mathrm{~m}^{2}$. The project is planned to consist of ground and two typical floors.

In order to investigate the settlement of the road tunnels due to the construction of the building, technical report was presented (Mazek et al., 2005). The results showed that the estimated settlement of the road tunnels was found to be within the allowable limit of $10 \mathrm{~mm}$. Modeling of such problem should include the details of tunnel construction phases and the associated stresses in and around the tunnels. To assess and predict the behavior of the tunnels due to construction of the proposed building, 2-D finite element model is used. A nonlinear stress-strain constitutive model is adopted for the soil surrounding the tunnel. A yield function of the Mohr-Coulomb type and a plastic potential function of the DruckerPrager type are employed. In addition, linear elastic behavior is assumed for the tunnel lining. The 2-D effects on the performance of the tunnel system are examined. The effects are expressed in terms of the settlement and radial displacement of the tunnel lining as well as the vertical displacement at different locations at the crossing zone, when the proposed building is constructed over El Azhar road tunnels.

\section{FINITE ELEMENT MODEL}

The finite element computer program (COSMOS/M) has been used in this study. The finite element model takes into account the effects of the vertical overburden pressure, the lateral earth pressure, the nonlinear properties of the soils and the linear properties of the road tunnel lining. Figure 1 shows the configuration of El-Azhar road tunnels and the proposed building. The soil, the tunnel lining, and the interface medium are simulated using appropriate finite elements. Numerical modeling of the tunnels and the proposed building reflect the ground continuum, the road tunnels, and the proposed building. In addition, the compatibility and equilibrium condition at the interface between soil and the tunnel system are idealized in the numerical model. 2-D plane strain elements are used for modeling the soil media and 2-D beam elements for modeling the tunnel lining. Three-node triangle plane strain elements are adopted to simulate behavior of the soil media, as shown in Figure 2.

The 2-D finite element mesh is shown in Figure 2. The vertical boundaries of the 2-D finite element model are restrained by roller supports to prevent a movement normal to the boundaries. The horizontal plane at the bottom of the mesh represented a rigid bedrock layer and the movement at this plane is restrained in all directions. The movement at the upper horizontal plane is free to simulate a free ground surface.

The lining is composed of $40 \mathrm{~cm}$ thickness segments. The stiffness at the joint may be appreciable less than elsewhere. The segments joints are never aligned along the tunnel and the thickness reduction is not as local as it is simulated in the model, which is conservative. The computed normal forces and bending moment values must comply with the strength of the $40 \mathrm{~cm}$ thick reinforced segments and the $24 \mathrm{~cm}$ thick joints between segments. 
El-Azhar road tunnels were constructed in 1999. The construction of the proposed building above the road tunnels later in 2005 caused the soil around the road tunnel respond to unload. The nonlinear properties of soils, the depth of the road tunnels, and the confining pressure are included to study their effects on the settlement and radial displacement of the road tunnels. Studies have been made with the road tunnels, as it exists in the field at depth $20 \mathrm{~m}$ from the ground surface.

Different nonlinear properties of soil have been chosen to realistically simulate the behavior of the different soils along El-Azhar road tunnels (Ezzeldin, 1999; Mazek, 2003; National Authority for Tunnels, 1999). Moreover, the soil-tunnel excavation and the construction of the proposed building have been idealized using the yielding function of the Mohr-Coulomb type and the plastic potential function of the Drucker-Prager type.

\section{PROPERTIES OF TUNNEL LINING AND SOIL}

Since the tunnels are constructed before the construction of the proposed building, further displacements would be induced in the road tunnels after the construction of the proposed building. The settlement and additional radial displacement of the road tunnels have been calculated in this study.

The radial displacements are computed at the invert and crown of the road tunnels. The final diameter is $8.35 \mathrm{~m}$ and the excavation diameter is $9.15 \mathrm{~m}$. The circular tunnel lining consists of seven segments and one key. The length of the ring is $1.5 \mathrm{~m}$. The characteristics of the tunnels are tabulated in Table 1.

Table 1: Characteristics of the tunnel lining

\begin{tabular}{|c|c|c|c|}
\hline$v$ & $E_{b}\left(\mathrm{t} / \mathrm{m}^{2}\right)$ & $(\mathrm{t}) \mathrm{cm}$ & $\mathbf{f}_{\mathbf{c}}\left(\mathbf{t} / \mathbf{m}^{2}\right)$ \\
\hline 0.2 & $2.1 \times 10^{6}$ & 40 & 4000 \\
\hline
\end{tabular}

In Table 1, $v$ is Poisson's ratio of tunnel liner, $E_{b}$ is the elastic modulus of the tunnel lining, $\mathrm{t}$ is the thickness of tunnel lining, and $f_{c}$ is the compressive strength of concrete.

The project area under analysis lies within the alluvial plain, which covers the major area of the lowland portion of the Nile valley in Cairo vicinity (Campo and Richards, 1998; ElNahhass et al., 1994; Mazek et al., 2001b; National Authority for tunnels, 1993, 1999). Site investigations along the project alignment have indicated that the soil profile consists of a relatively thin surficial fill layer ranging from two to four metres in thickness. A natural deposit of stiff, overconsolidated silty clay underlies the fill. This deposit includes occasional sand and silt partings of thickness from four to ten metres. Beneath the clay layer, there is a thick alluvial sand that extends down to bedrock, which is well below El-Azhar road tunnels. The watertable varies between 2-4 $\mathrm{m}$ from the ground surface.

The upper few metres of this alluvial sand are parts of a transition layer of highly interbedded clay silt and fine sand. Below the transition layer, the alluvial sand layer is more uniform with coarse to fine sand, which occasionally contains layers of silt to clayey silt that varies in thickness from a few centimetres to several decimetres. Lenses of gravel and cobbles, up to several metres thick, may also be present at depths of 25 to 30 metres. Soil parameters are presented in Table 2 .

Table 2: Geotechnical properties 
Proceedings of the 6th ICCAE Conf. 16-18 May, 2006

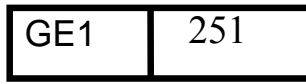

\begin{tabular}{|c|c|c|c|}
\hline Soil parameter & Fill & $\begin{array}{c}\text { Silty clay } \\
\text { (drain condition) }\end{array}$ & Sand \\
\hline$\gamma_{\mathbf{b}}\left(\mathbf{t} / \mathbf{m}^{\mathbf{3}}\right)$ & 1.8 & 1.9 & 2.0 \\
\hline $\mathbf{k}_{\mathbf{0}}$ & 0.58 & 0.8 & 0.37 \\
\hline $\mathrm{U}_{\mathbf{s}}$ & 0.4 & 0.35 & 40 \\
\hline$\phi($ Degree $)$ & 25 & 26 & 0 \\
\hline $\mathrm{C}\left(\mathrm{t} / \mathrm{m}^{2}\right)$ & 1.0 & 0 & 10.0 to end \\
\hline Depth $(\mathrm{m})$ & 0.0 to 4.0 & 4.0 to 10.0 & 40 \\
\hline
\end{tabular}

In Table $2, \gamma_{\mathbf{b}}$ is bulk density, $\mathbf{k}_{\mathbf{o}}$ is coefficient of lateral earth pressure, $v_{\mathbf{s}}$ is Poisson's ratio, $\phi$ is the angle of internal friction for the soil, and $\mathrm{C}$ is cohesion.

Since soil behavior is generally inelastic, the constitutive relationship adopted in the analysis is an elasto-plastic model. The Mohr-Coulomb criterion is adopted. Excavations of the road tunnels and the proposed building foundation have been simulated by removing elements from the excavated boundary. The friction angles $(\phi)$ adopted for the layers have been obtained using laboratory test results from reconstituted samples. The vertical initial drained modulus $\left(E_{v}\right)$ is related to the effective pressure based on Janbu empirical equation (Janbu, 1963), which is given by Eq. 1

$$
E_{v}=m p_{a}\left(\frac{\sigma_{3}}{p_{a}}\right)^{n}
$$

In which, the modulus number $(\mathrm{m})$ and the exponent number $(\mathrm{n})$ are both pure number and $\left(p_{a}\right)$ is the value of the atmospheric pressure expressed in appropriate units.

Geotechnical parameters have been presented in NAT documents (National Authority for Tunnels, 1993 and 1999). The soil parameters used for elasto-plastic finite element analysis for different types of the soil are presented in Table 3 (Mazek, 2005; National Authority for Tunnels, 1993 and 1999).

Table 3: Soil parameters

\begin{tabular}{|c|c|c|c|c|c|c|c|c|}
\hline Material & $\mathrm{m}$ & $\mathrm{n}$ & $C_{u}(\mathrm{kPa})$ & $\mathrm{C}(\mathrm{kPa})$ & $\phi_{u}$ & $\phi$ & $v_{u}$ & $v$ \\
\hline Fill & 300 & 0.74 & 50 & 10 & 20 & 25 & 0.4 & 0.4 \\
\hline Silty Clay & 350 & 0.60 & 75 & 0 & 0 & 26 & 0.45 & 0.35 \\
\hline Sand & $400-600$ & $0.5-0.6$ & 0 & 0 & - & 40 & - & 0.3 \\
\hline
\end{tabular}

In Table 3, $C_{u}$ is the undrained cohesion, $\mathrm{C}$ the effective cohesion (drained), $\phi_{u}$ is angle of internal friction in terms of total stress (for unsaturated fill $\phi_{u}=20^{\circ}$ ), $\phi$ is the effective angle of internal friction (drained), $v_{u}$ is the undrained Poisson's ratio, and $v$ is the drained Poisson's ratio.

The finite element analysis of the tunnel is carried out to simulate the construction of both the road tunnels and the proposed building. The construction of the road tunnels was under the initial in-situ stress condition. The excavation of the proposed building causes the soil around the road tunnel system to respond in an unloading manner, and unload moduli is appropriate during this stage. Under the unload-reload condition, Duncan et al. (1980) found that unload 
and reload modulus $\left(E_{u r}\right)$ are similar and are 1.2-3 times the vertical drained modulus $\left(E_{v}\right)$. Byrne et al. (1987), based on tests on granular soils, found $E_{u r} / E_{v}$ in the range 2-4. A shear modulus $\left(G_{v h}\right)$ is used in the finite element analysis. The ratio of the shear modulus to the vertical modulus $G_{v h} / E_{v}$ is about 0.35 in initial loading condition for sand. In unloading condition, the $G_{v h} / E_{v}$ ratio is about 0.25 for sand. Effective stress is used in the finite element analysis, as the road tunnels are located in sand.

The reaction forces of the proposed building are applied at the foundation level in order to check the behavior of the tunnel liners and their safety. $1.2 \mathrm{t} / \mathrm{m}^{2}$ surcharge load per floor is considered in the analysis. For every model, the surcharge loads are included, as shown in Figure 1. The study assumes that the load of the building per floor related to the structure is $1.2 \mathrm{t} / \mathrm{m}^{2}$.

\section{STRESS IN SOIL}

The stresses in the soil have undergone two stages of change. The first stage corresponds to the construction of tunnels and the second stage to the construction of the proposed building.

At the first stage, the loading steps of the tunnel construction have been simulated using the 2D finite element analysis. First, the initial principal stresses are computed with the absence of the tunnels. Second, the excavation of the road tunnels is modeled by means of the finite element method. The excavation has been simulated by the removal of those elements inside the boundary of the tunnel surface to be exposed by the excavation. Third, the movement and stress changes induced in soil media are calculated. Fourth, the calculated changes in stresses are then added to the initial principal stresses computed from the first step to determine the final principal stresses resulting from the tunnel construction. These final induced principal stresses are considered as the initial principal stresses for the second stage (Stage 1).

At the second stage, the loading steps of the building construction are also simulated using the 2-D finite element analysis. First, the initial principal stresses for this stage have been computed as mentioned above (Stage 1). Second, the removal of the surface loads is modeled by the removal of those elements inside the boundary of the proposed building excavations. Third, the movement and stress changes induced in the soil media are calculated. Fourth, the final stresses due to the construction of the proposed building at different cases of loading are computed.

\section{RESULTS OF THE FINITE ELEMENT ANALYSIS OF THE TUNNELS}

With the vertical separation between the tunnels and the foundation level of the proposed building being constant $18 \mathrm{~m}$, the finite element analysis is conducted. The geotechnical properties of the soil for this part of the study have been listed in Table 3.

The numerical analysis is carried out under the unload reload modulus $\left(E_{u r n}\right)$ for the soil based on Janbu's equation [Equation 2] applying different nonlinear soil parameters. The rang of maximum surface settlement before building construction is in the range of $6-8 \mathrm{~mm}$, within the previous monitoring values during tunnel installation (National Authority for Tunnels, 1999).

The analysis is performed through main stages as follows. The loading of the first stage includes: (1) initial soil condition before the tunnels; (2) removal of the soil inside the 
boundary of the tunnel surface; and (3) construction of the road tunnel liners (Stage 1). The loading of the second stage includes: (1) initial soil condition before construction of the building foundation (Stage 1); (2) removal of surface loads and excavation of proposed building foundations (Stage 2); and (3) construction of the proposed building (foundation, ground floor, and two typical floors) by applying its loads at foundation level (Stage 3 to 6).

The maximum bending moment $\left(\mathrm{M}_{\max }\right)$ and the associated normal forces $(\mathrm{N})$ typical on the tunnel lining are presented in Table 4 at different loading conditions taking into account the overburden pressure, the lateral earth pressure, and the pore water pressure. In addition, the maximum normal forces $\left(\mathrm{N}_{\max }\right)$ and the associated bending moments $(\mathrm{M})$ are also tabulated in Table 4.

Table 4: Straining action generated on southern tunnel lining at different load stages

\begin{tabular}{|c|c|c|c|c|}
\hline Case of loading & $\mathrm{M}_{\max }(\mathrm{m} . \mathrm{t} / \mathrm{m})$ & $\mathrm{N}$ (associated) $(\mathrm{t} / \mathrm{m})$ & $\mathrm{N}_{\max }(\mathrm{t} / \mathrm{m})$ & $\mathrm{M}$ (associated) $(\mathrm{m} . \mathrm{t} / \mathrm{m})$ \\
\hline Stage 1 & -2.459 & 290.9 & 293.9 & -2.213 \\
\hline Stage 2 & -2.263 & 278.7 & 280.1 & -2.057 \\
\hline Stage 3 & -2.585 & 299 & 303.1 & -2.315 \\
\hline Stage 4 & -2.657 & 303.9 & 308.7 & -2.375 \\
\hline Stage 5 & -2.732 & 308.9 & 317.4 & -2.438 \\
\hline Stage 6 & -2.786 & 312.5 & 318.5 & -2.482 \\
\hline
\end{tabular}

Due to the excavation of the soil up to the proposed building foundation level (Loading 1), the results find that there is heave at the crown and the invert of the south tunnel, as shown in Fig. 3.

The final vertical displacement of the surrounding soil at the crossing zone is estimated due to the construction of the proposed building. Figures 4 to 6 show the influence of the building construction on displacement, and stress changes of the surrounding soil around the tunnel. The final vertical soil displacements at different levels along the centerline of the southern road tunnel are settled dawn. After the achievement of the proposed building construction, the results show that the soil at the foundation level of the building settles downward, as presented in Fig. 4. The results also show that the soil above the crown and under the invert of the southern road tunnel settles downward, as shown in Fig. 5. The final vertical soil stresses around the tunnel system after the construction of the proposed building is also plotted in Fig.6.

Based on the 2-D finite element analysis, the following results can be concluded; (1) the internal stresses within the concrete lining of the tunnels are not exceed the allowable values due to the construction of the proposed building; (2) the maximum expected vertical deformation of the tunnel cross section is $9.8 \mathrm{~mm}$. Hence, no risk is expected due to the construction of the building.

\section{CONCLUSIONS AND RECOMMENDATIONS}

A 2-D nonlinear finite element analysis has been used to study the construction of a proposed building above the southern El-Azhar road tunnels. The analysis takes into account the changes in stress, the non-linear behavior of the soil, and construction the progress, etc. The 
following conclusions can be drawn regarding the performance of the tunnel under the effects of different factors.

- The proposed 2-D numerical model is applied to analyze and predict the performance of the tunnel system under the new building construction effect.

- A tunnel monitoring program is under way for the tunnel in the same project. The monitoring program should confirm the range of the calculated deformations. The result verification should be performed before, during, and after the construction of the building.

- There is no risk on El-Azhar road tunnels if the technical specification for soil-tunnel modeling and a prefect supervision on management system are followed.

\section{ACKNOWLEDGMENT}

The authors acknowledge the National Authority for Tunnels (NAT) and the Egyptian Tunneling Society for their technical support.

\section{REFERENCES}

- Byrne, P.M., Cheung, H., and Yan, L. (1987). Soil parameters for deformation analysis of sand masses. Canadian Geotechnical Journal. 24, 366-376.

- COSMOS/M program. (2001). Structural Research and Analysis Corporation. Los Angeles, California. USA.

- Compo, D.W., and Richards, D.P. (1998). Geotechnical challenges faced on line 2 of the Greater Cairo Metro System. ASCE, Big dig around the world. USA.

- Duncan, J.M., Byrne, P.M., Wong, K.S., and Mabry, P. (1980). Strength, stress-strain and bulk modulus parameters for finite element analysis of stresses and movements in soil masses. University of California, Berkeley, CA. Report no. UCB/GT/80-01.

- Janbu, N. 1963. Soil compressibility as determined by oedometer and triaxial tests. European conference on soil mechanics of foundation engineering. Wiesbaden. Germany. Vol. 1, pp. 19-25.

- El-Nahhass, F.M., Ahmed, A.A., El-Gammal, M.A., and Abdel Rahman, A.H. (1994). Modeling Braced Excavation for Subway station. Proceedings of the international congress on tunneling and ground condition, Abdel Salam (ed.), Cairo, Egypt. Published by Balkema.

- Ezzeldine, O.Y. (1999). Estimation of the Surface Displacement Field Due to Construction of Cairo Metro Line El-Khalafawy- St.Thereses. Tunneling and underground space technology, Vol. 14, No. 3, pp. 267-279. Published by Elsevier science Ltd.

- Mazek, S.A., Law, K.T., and Lau, D.T. (2001). 3-D Analysis on the Performance of a Grouted Tunnel. Canadian Geotechnical Conference. Calgary. Canada. Vol. 1, pp. 111-119.

- Mazek, S.A. 2003. Soil structure interaction modeling and analysis of tunnels. Ph.D. thesis, Civil and Environmental Engineering Department, Carleton University, Ottawa, Canada.

- Mazek S.A., Aggour, A.A., and Belal, A.M. (2005). Technical report for evaluation of building construction influence on El-Azhar road tunnels approved by National Authority For Tunnels.

- National Authority for Tunnels (NAT), 1993 and 1999, Project Documents. 
Proceedings of the 6th ICCAE Conf. 16-18 May, 2006
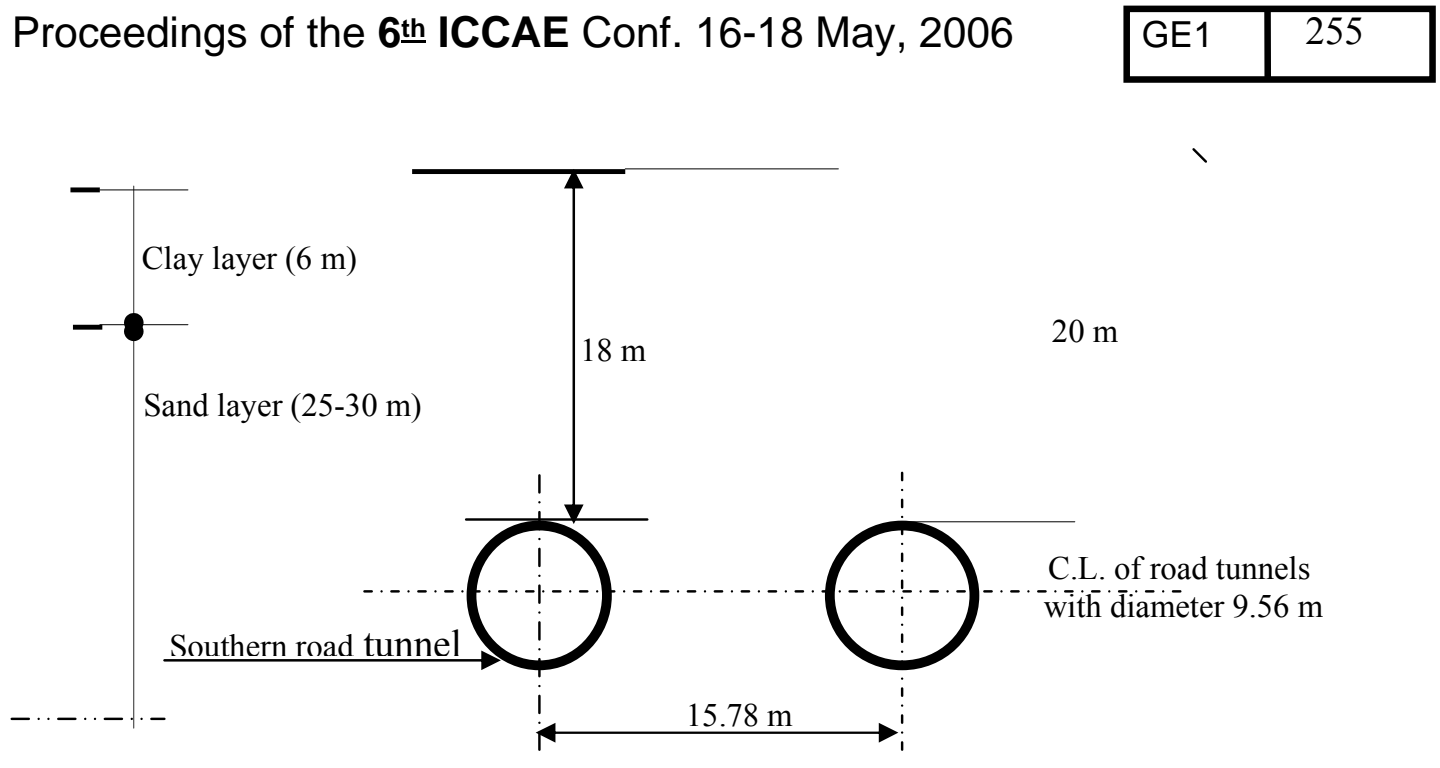

Figure 1. Cross section at the station of the proposed building over El-Azhar road tunnels

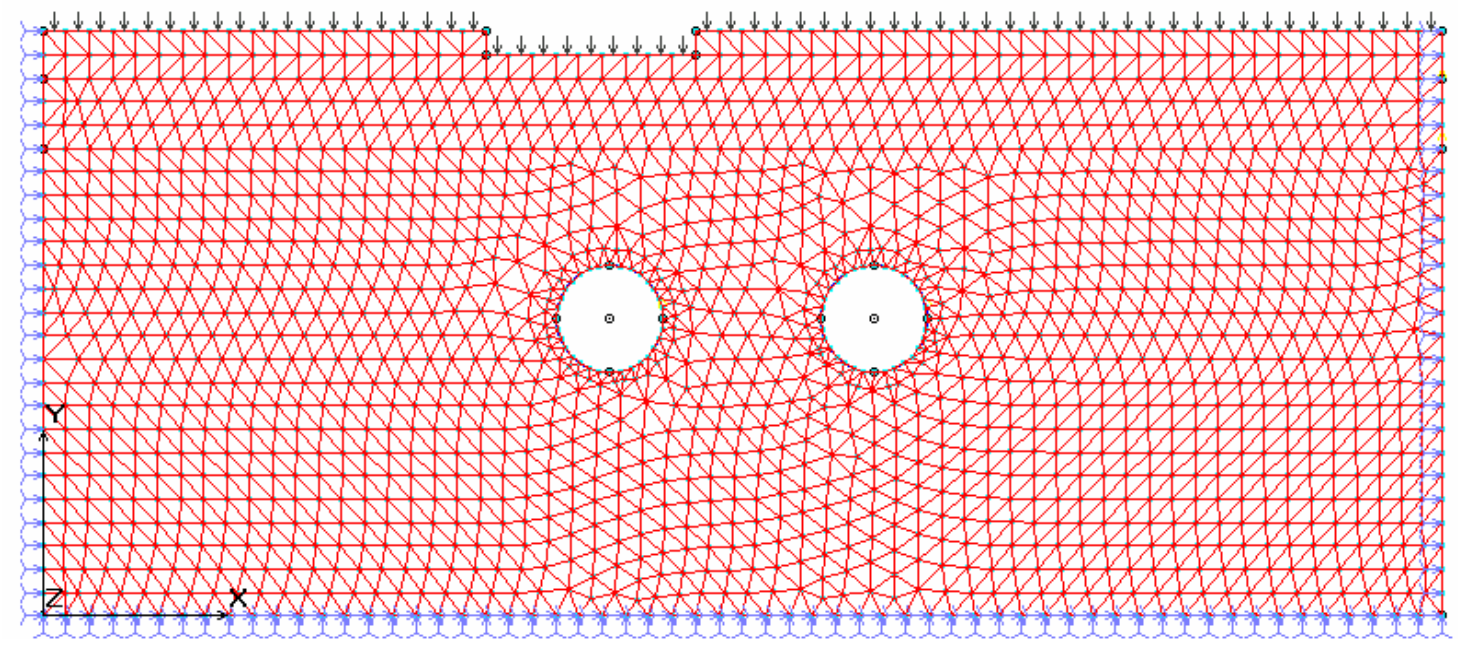

Fig. 2: 2-D finite element model of tunnel 


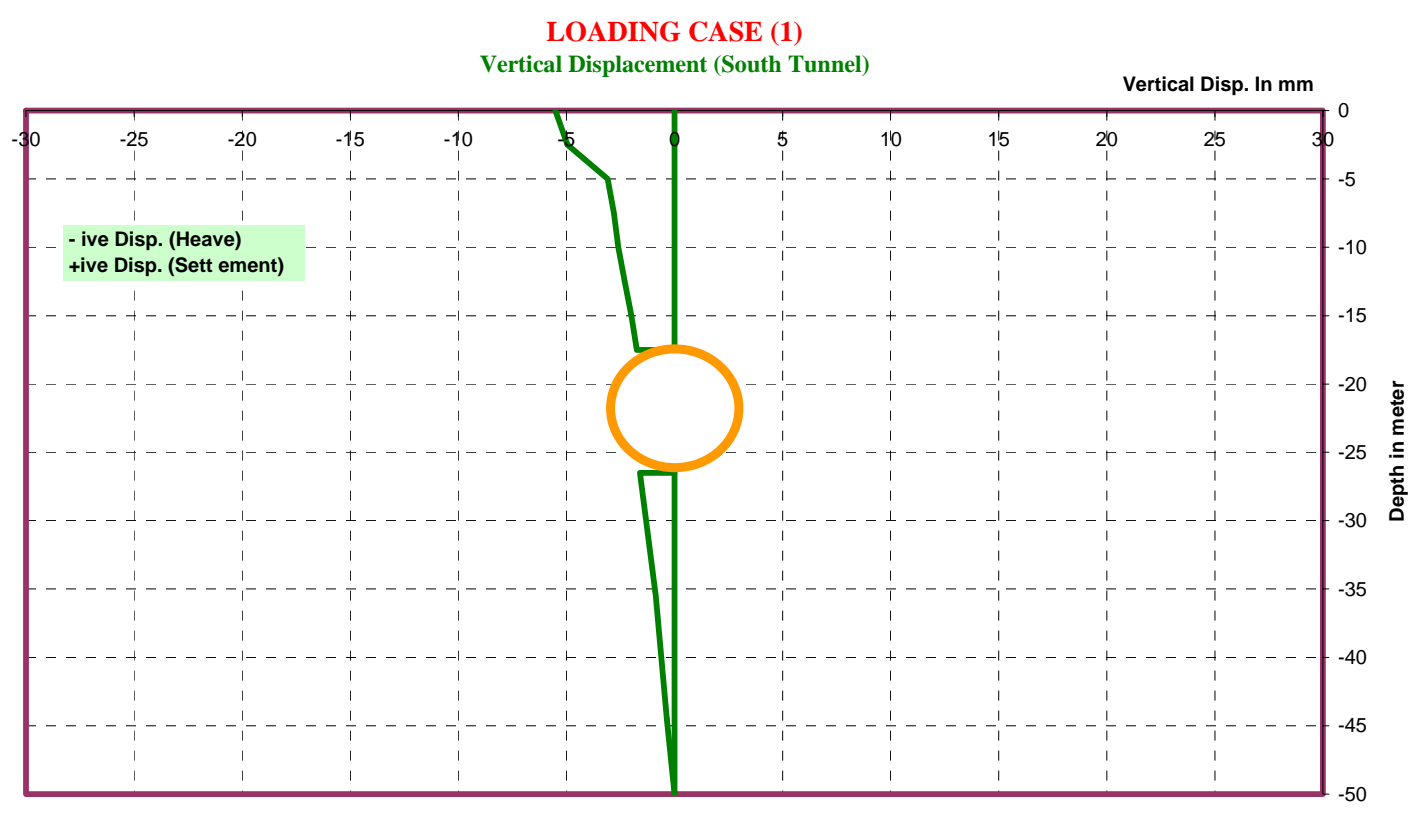

Fig. 3: Vertical soil displacement along the centerline of the south road tunnel after the excavation of the soil up to the proposed building foundation

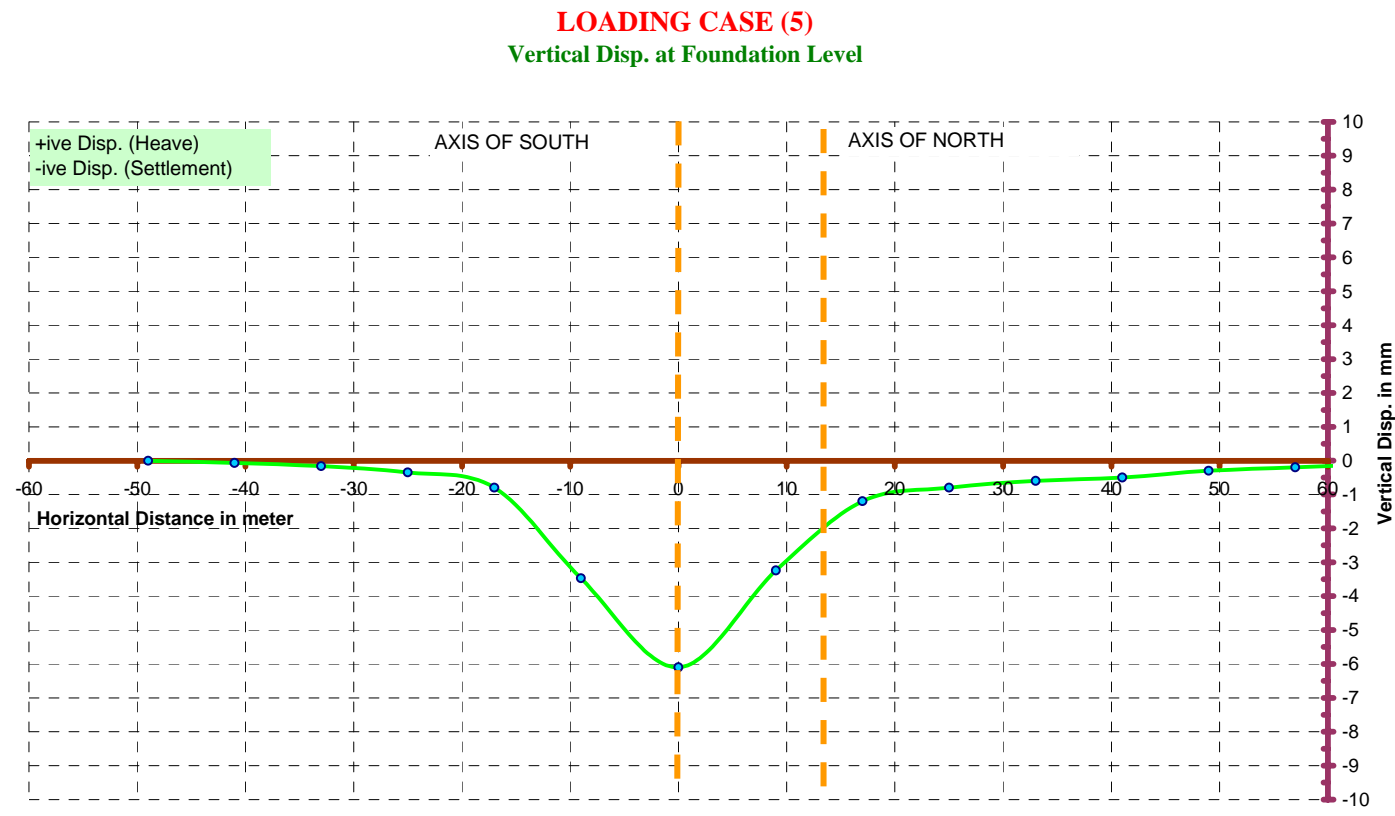

Fig.4: Vertical displacement of soil at the foundation level of the proposed building after achievement of the building construction 
LOADING CASE (5)

Vertical Disp. at Crown Level

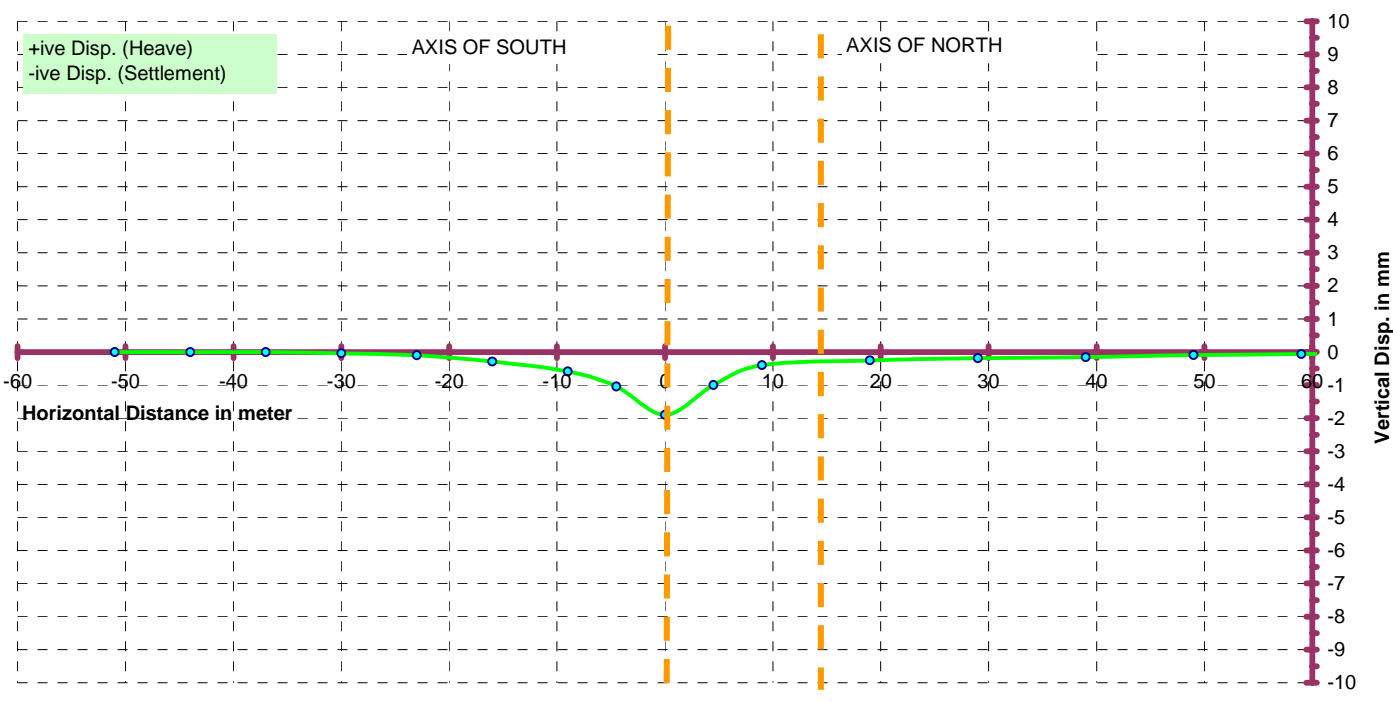

Fig.5: Vertical displacement of soil at the crown level of the south tunnel after achievement of the building construction

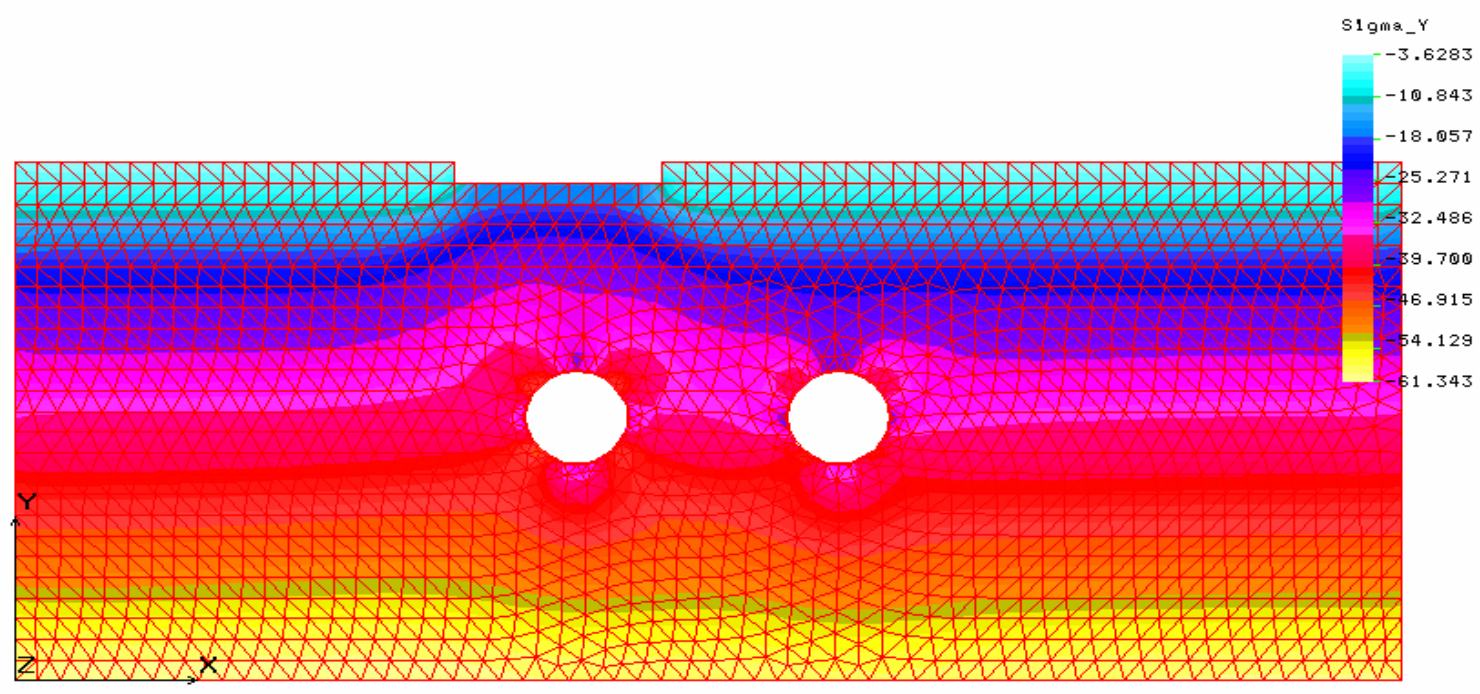

Fig.6: Final vertical soil stress around the tunnels after achievement of the building construction 